\title{
Loss of relational continuity of care in schizophrenia: associations with patient satisfaction and quality of care
}

Rahil Sanatinia, Violet Cowan, Kirsten Barnicot, Krysia Zalewska, David Shiers, Stephen J. Cooper and Mike J. Crawford

\section{Background}

Users of mental health service are concerned about changes in clinicians providing their care, but little is known about their impact.

\section{Aims}

To examine associations between changes in staff, and patient satisfaction and quality of care.

\section{Method}

A national cross-sectional survey of 3379 people aged 18 or over treated in secondary care for schizophrenia or schizoaffective disorder.

\section{Results}

Nearly $41.9 \%$ reported at least one change in their key worker during the previous 12 months and $10.5 \%$ reported multiple changes. Those reporting multiple changes were less satisfied with their treatment and less likely to report having a care plan, knowing how to obtain help when in a crisis or to have had recommended physical health assessments.

\section{Conclusions}

Frequent changes in staff providing care for people with psychosis are associated with poorer quality of care. Greater efforts need to be made to protect relational continuity of care for such patients.

\section{Declaration of interest}

M.J.C. was co-chair of the expert advisory group on the NICE quality standard on Service User Experience in Adult Mental Health. S.J.C. has previously been a member of the Health and Social Care Board Northern Ireland Formulary Committee. D.S. received a speaker's fee from Janssen Cilag in 2011. He is a topic expert on NICE guideline for psychosis and schizophrenia in children and young people and a board member of National collaborating Centre for Mental Health.

\section{Copyright and usage}

(c) The Royal College of Psychiatrists 2016. This is an open access article distributed under the terms of the Creative commons Non-Commercial, No Derivatives (CC BY-NC-ND) license.
Schizophrenia is a long-term condition for which most people receive medication and psychosocial interventions over many years. National guidelines emphasise the importance of long-term supportive therapeutic relationships with staff to ensure that patients receive the care that they need. ${ }^{1}$ In several countries, key worker, case-manager and care-coordinator roles have been developed to try to ensure that people with severe mental illness receive consistent and coordinated care. ${ }^{2,3}$ Although mental health services have focused on making sure that people with severe mental illness have long-term contact with mental health teams, service users may be more likely to value long-term contact with the same person. ${ }^{4}$ It is therefore concerning that people with schizophrenia report that changes in clinical staff are common and can disrupt the care they receive. ${ }^{5}$ Despite the importance of this issue, there is limited information about how often people with schizophrenia have changes in clinical staff who deliver their care. Most studies have been limited to small numbers of services and have had insufficient power to detect clinically important differences in patient outcomes. ${ }^{6}$ The largest study to date, designed to look at the impact of introducing a case management system, involved 661 people with severe mental illness from Ohio and Maryland, USA, of whom $60 \%$ had a primary diagnosis of schizophrenia. ${ }^{7}$ Although a larger number of patients in the first cohort had had a change of case manager at 12 months, the team found no differences in levels of hospitalisation, satisfaction with care or social functioning between cohorts.

The National Audit of Schizophrenia is an audit of care received by people with schizophrenia and schizoaffective psychosis in England and Wales. ${ }^{8}$ All providers of state-funded secondary care mental health services take part in the audit. The audit examines the quality of care that people receive against nationally agreed standards. Questions on changes in clinical staff were included in the second round of the audit and provided an opportunity to examine whether such changes are associated with differences in the quality of care that people with severe mental illness receive. We performed secondary analyses on the data from the audit to examine the proportion of people with schizophrenia who experienced changes in their key worker and/or psychiatrist over the preceding 12 months and whether such changes were associated with patient satisfaction and the quality of care that people received.

\section{Method}

Between August and November 2013, all 64 mental health trusts in England and Health Boards in Wales were asked to survey a random sample of 200 service users with an ICD-10 diagnosis of schizophrenia or schizoaffective disorder, who were aged 18 years or older and had been under the care of community mental health teams in the previous 12 months. Details of the methods used have been published elsewhere. ${ }^{8}$ The content of the patient survey was based on national guidelines for the care of people with schizophrenia ${ }^{9}$ and a quality standard on patient experience in mental health ${ }^{1}$ and was developed with input from an expert reference group of users and providers of mental health services. Service users who gave feedback on a draft version of the questionnaire asked that questions about age and other demographic factors be removed because of concerns that potential respondents might be less likely to express their views if they thought this information could be used to identify them. However, 
three of the trusts that took part in the survey agreed to link survey forms with case-note audit data, which allowed us to compare the demographic characteristics of a sample of people who did and did not complete the questionnaire.

The survey contained two questions on relational aspects of continuity of care: 'Has there been a change in your key worker or care coordinator in the last year?' and 'Has there been a change in your psychiatrist in the last year?' To each question, patients were asked to indicate whether there had been no change, one change, or two or more changes to their key worker or psychiatrist. The survey also included a Patient Reported Experience Measure, the Patient Satisfaction Questionnaire ${ }^{10}$ and a series of questions on access to services, and whether they had received recommended interventions and treatments for their physical and mental health.

We did not seek ethical approval for this national clinical audit. Neither the National Research Ethics Service nor the Ethics and Confidentiality Committee of the National Information Governance Board identified any issues with the methodology when we checked with them before the start of the audit.

\section{Data analysis}

We calculated the number and proportion of patients who reported no change, one change or more than one change in their key worker and/or psychiatrist. We then compared self-reported outcomes between those who reported no changes in key worker with those who reported one change and those who reported more than one change in key worker, and similarly with changes in psychiatrist. We used multilevel linear regression (patient satisfaction outcome) and multilevel logistic regression (all other outcome variables), with a random effect for NHS trust to estimate and control for clustering of the dependent variables within trusts, using GENLINMIXED in SPSS version $22 .{ }^{11}$ For three of the outcome variables (access to key worker, family therapy and employment support), the variance between trusts was estimated as zero, and the random effect was therefore omitted from the model.

\section{Results}

A total of 3379 patients returned the survey, a response rate of $26.4 \%$ on 12800 questionnaires (64 trusts $\times 200$ questionnaires each). Demographic and clinical characteristics of those who did and did not respond to the survey in the three trusts from which these data were available are presented in Table 1. There were small trends for men to be more likely to respond than women, for those who were White to be more likely to respond, and for respondents to have had longer-term contact with services.

Most patients $(n=3296,97.5 \%)$ provided information about whether there had been a change in their key worker. The number and proportion of people reporting changes in their key worker and psychiatrist are presented in Table 2. In total, 1107 (41.9\%) reported a change in their key worker and 1212 (36.8\%) a change in their psychiatrist. Of the 1107 who reported a change in their key worker in the last 12 months, 525 (47.4\%) also reported a change in their psychiatrist during this period.

There were marked differences in the proportion of people who reported changes in clinical staff across different service providers. In some trusts as few as a quarter of patients reported a change in key worker during the previous 12 months, whilst in others threequarters of patients reported such a change. The proportion reporting a change in their psychiatrist was $27.4 \%$ and ranged from $8.5 \%$ to $50.0 \%$. Although there was a significant difference between NHS trusts in the likelihood of a change in psychiatrist (random intercept variance $=0.08, P<0.01$ ), there were no significant differences between NHS trusts in the likelihood of key worker changes (random intercept variance $=0.04, P=0.13$ ). There were significant differences between NHS trusts in patients' satisfaction with care, knowledge of how to access help at times of crisis and likelihood of having a care plan (random intercept $P<0.05)$.

Associations between changes in key worker or psychiatrist, experiences of care and access to services are presented in Table 3. Compared with patients whose healthcare professional had not changed in the past 12 months, patients who had experienced more than one change of key worker or psychiatrist reported significantly lower treatment satisfaction, were less likely to feel they had been helped by services and were less likely to know how to access their key worker or how to access help appropriately at times of crisis. A single change of healthcare professional had significant, but smaller, negative effects on treatment satisfaction

\begin{tabular}{|c|c|c|c|c|}
\hline Characteristics & Completed the survey, $N=61$ & Not completed, $N=240$ & Difference in proportions/means, $(95 \% \mathrm{Cl})$ & $P$ \\
\hline Age mean (s.d.) & $51.39(11.15)$ & $49.43(12.07)$ & $-1.97(-5.32$ to 1.39$)$ & 0.249 \\
\hline \multicolumn{5}{|l|}{ Gender $n(\%)$} \\
\hline Male & 45 (73.77) & $153(63.75)$ & $10.02(-3.5$ to 21.3$)$ & 0.174 \\
\hline Female & $16(26.2 \%)$ & 87 (36.3\%) & & \\
\hline \multicolumn{5}{|l|}{ Ethnicity, $n(\%)$} \\
\hline White & 48 (78.7\%) & $159(66.3 \%)$ & $12.44(-0.67$ to 22.89$)$ & 0.500 \\
\hline Asian or Asian British & $3(4.9 \%)$ & $21(8.8 \%)$ & $-3.83(-9.18$ to 5.24$)$ & \\
\hline Black or Black British & 8 (13.1\%) & $41(17.1 \%)$ & $-3.97(-12.2$ to 7.53$)$ & \\
\hline Chinese/other & $1(1.6 \%)$ & 6 (2.5\%) & $-0.86(-6.35$ to 4.01$)$ & \\
\hline Mixed & $0(0.0 \%)$ & $5(2.1 \%)$ & $-2.08(-4.78$ to 3.96$)$ & \\
\hline Not stated & $1(1.6 \%)$ & $8(3.3 \%)$ & $-1.69(-5.57$ to 5.08$)$ & \\
\hline \multicolumn{5}{|l|}{ Time since diagnosis (\%) } \\
\hline Between 1 and 2 years & $0(0.0 \%)$ & $4(1.7 \%)$ & $-1.67(-4.34$ to 4.21$)$ & 0.183 \\
\hline Up to 4 years & $3(4.9 \%)$ & $22(9.2 \%)$ & $-4.25(-9.64$ to 4.85$)$ & \\
\hline Up to 10 years & 12 (19.7\%) & 67 (27.9\%) & $-8.24(4.54$ to -18.27$)$ & \\
\hline More than 10 years & 46 (75.4\%) & 147 (61.3\%) & 14.16 (0.69 to 25.21$)$ & \\
\hline \multicolumn{5}{|l|}{ Care team, $n(\%)$} \\
\hline Assertive outreach team & $3(4.9 \%)$ & $17(7.1 \%)$ & $-2.17(-6.8$ to 7.28$)$ & 0.085 \\
\hline Community team & $57(93.4 \%)$ & $194(80.8 \%)$ & 12.61 (2.44 to 19.36$)$ & \\
\hline Crisis resolution team & $0(0.0 \%)$ & 0 (0.0\%) & - & \\
\hline Early intervention service & $0(0.0 \%)$ & $4(1.7 \%)$ & $-1.67(-4.34$ to 4.21$)$ & \\
\hline Other & $1(1.6 \%)$ & $25(10.4 \%)$ & $-8.78(-13.48$ to 0.98$)$ & \\
\hline
\end{tabular}


Table 2 Number and proportion of patients reporting changes in key worker and psychiatrist during the previous 12 months (and range in the proportion across all 64 trusts)

\begin{tabular}{|c|c|c|c|c|c|c|}
\hline & \multicolumn{2}{|c|}{ No change } & \multicolumn{2}{|c|}{ One change } & \multicolumn{2}{|c|}{ More than one change } \\
\hline & $n(\%)$ & Range & $n(\%)$ & Range & $n(\%)$ & Range \\
\hline Key worker & 1535 (58.1) & $25.0-75.0 \%$ & $829(31.4)$ & $17.5-57.1 \%$ & $278(10.5)$ & $0.0-23.1 \%$ \\
\hline Psychiatrist & 2084 (63.2) & $33.3-61.5 \%$ & $902(27.4)$ & $8.5-50.0 \%$ & $310(9.4)$ & $0.0-25.9 \%$ \\
\hline
\end{tabular}

and feeling helped but no significant effect on knowing how to access help in a crisis.

There were also stronger associations between multiple compared with single changes in healthcare professional with process of care and interventions received (Table 4). Compared with patients with no change of healthcare professional, patients with more than one change in either their key worker or psychiatrist were less likely to feel involved in decisions about their medication or to have had a discussion about medication side-effects. Additionally, patients with more than one change in psychiatrist were less likely to have completed a care plan or had physical health checks completed.

\section{Discussion}

Data from this national cross-sectional survey of people treated for schizophrenia and schizoaffective psychosis show that changes in clinical staff that provide mental healthcare are common. We found clear associations between changes in clinical staff and a number of measures of patient experience and quality of care. Not only were patients who experienced changes in clinical staff less satisfied with the service they received, they were also less likely to report receiving care in keeping with recommended national guidelines. Differences between no change and just one change in psychiatrist or key worker were generally small, but when patients reported multiple changes, differences in outcomes were often marked. It is important if mental health services are to be effective that patients and carers have confidence that they can access effective help at times of crisis. ${ }^{12-14}$ Patients who reported multiple changes in key worker were far less likely to report knowing who to contact at times of crisis, increasingly the likelihood of delays in ensuring that people receive the help that they need when they are most vulnerable. Concerns about poor physical health and premature mortality among people with psychosis have led to increased efforts to screen for cardiovascular disease and other physical health conditions among people with schizophrenia. ${ }^{15,16}$
The results of this study show that people who have had multiple changes in their psychiatrist are less likely to report having had regular physical health checks. More than one change in either key worker or psychiatrist was also associated with patients reporting that they had not been involved in discussions about medication side-effects or decisions about treatment, factors which have been shown to influence attitudes to treatment among people with psychosis. ${ }^{17}$ We did not find associations between changes in clinical staff and whether patients had received cognitive behavioural therapy and family therapy. Most of those who responded to the survey had had contact with mental health services for over a decade, and it is possible that if patients did receive these interventions, it was at an earlier stage of their contact with mental health services.

\section{Strengths and limitations}

Data for this study were collected from all state-funded mental health services across England and Wales, and the sample was large enough to have sufficient power to examine clinically important differences in patient experience and care. However, the audit, and therefore this analysis, has a number of limitations. We relied on data provided by patients to assess the quality of care received and have no data on clinician reported outcomes. It is possible that response bias affected the information that participants provided. However, the pattern of responses (such as stronger associations between medical aspects of care and changes in psychiatrist compared with associations with changes in key worker) suggests this was limited. Cross-sectional studies do not provide a strong basis for establishing causality, and we do not know whether factors other than changes in clinical staff are responsible for differences in patient experience and the other outcomes we assessed. Nonetheless, our finding of a doseresponse relationship between the number of changes in clinical staff and quality of care, together with our finding that the strongest association was between multiple changes in staff and a

Table 3 changes in clinical staff, experience of care and access to services

\begin{tabular}{|c|c|c|c|c|c|c|c|c|c|c|}
\hline & \multicolumn{5}{|c|}{ Change in key worker } & \multicolumn{5}{|c|}{ Change in psychiatrist } \\
\hline & & $\begin{array}{l}\text { Mean or } N \\
\text { (s.d. or \%) }\end{array}$ & $\begin{array}{c}\beta \text { or } \\
\text { odds ratio }\end{array}$ & $\begin{array}{l}95 \% \\
\text { confidence } \\
\text { interval }\end{array}$ & $P$ & & $\begin{array}{l}\text { Mean or } N \\
\text { (s.d. or \%) }\end{array}$ & $\begin{array}{c}\beta \text { or odds } \\
\text { ratio }\end{array}$ & $\begin{array}{l}95 \% \\
\text { confidence } \\
\text { interval }\end{array}$ & $P$ \\
\hline \multirow{3}{*}{$\begin{array}{l}\text { Satisfaction with } \\
\text { care (s.d.) }\end{array}$} & No change & $10.1(2.5)$ & & & & No change & $9.9(2.6)$ & & & \\
\hline & 1 change & $9.9(2.6)$ & -0.33 & -0.58 to -0.07 & 0.01 & 1 change & $9.7(2.7)$ & -0.24 & -0.48 to -0.01 & 0.04 \\
\hline & $>1$ change & $8.9(3.0)$ & -1.54 & -1.93 to -1.16 & $<0.01$ & $>1$ change & $8.6(3.1)$ & -1.34 & -1.71 to -0.98 & $<0.01$ \\
\hline \multirow{3}{*}{$\begin{array}{l}\text { Service helped them } \\
\text { achieve their } \\
\text { aims (\%) }\end{array}$} & No change & 1348 (89) & & & & No change & $1775(87)$ & & & \\
\hline & 1 change & $686(85)$ & 0.70 & 0.54 to 0.90 & $<0.01$ & 1 change & $766(87)$ & 1.05 & 0.83 to 1.33 & 0.68 \\
\hline & $>1$ change & $215(80)$ & 0.48 & 0.34 to 0.67 & $<0.01$ & $>1$ change & $231(77)$ & 0.51 & 0.38 to 0.70 & $<0.01$ \\
\hline \multirow{3}{*}{$\begin{array}{c}\text { Know how to access } \\
\text { key worker (\%) }\end{array}$} & No change & $1414(95)$ & & & & No change & $1545(94)$ & & & \\
\hline & 1 change & 742 (94) & 0.85 & 0.59 to 1.22 & 0.37 & 1 change & 650 (93) & 0.86 & 0.60 to 1.24 & 0.42 \\
\hline & $>1$ change & $235(88)$ & 0.42 & 0.27 to 0.66 & $<0.01$ & $>1$ change & $190(87)$ & 0.40 & 0.26 to 0.62 & $<0.01$ \\
\hline \multirow{3}{*}{$\begin{array}{l}\text { Know how to seek } \\
\text { help at times of } \\
\text { crisis (\%) }\end{array}$} & No change & $1139(77)$ & & & & No change & $1502(75)$ & & & \\
\hline & 1 change & $620(78)$ & 1.06 & 0.86 to 1.31 & 0.59 & 1 change & $649(75)$ & 0.99 & 0.82 to 1.19 & 0.89 \\
\hline & $>1$ change & $176(65)$ & 0.56 & 0.42 to 0.74 & $<0.01$ & $>1$ change & $196(66)$ & 0.66 & 0.51 to 0.86 & $<0.01$ \\
\hline
\end{tabular}




\begin{tabular}{|c|c|c|c|c|c|c|c|c|c|c|}
\hline & \multicolumn{5}{|c|}{ Change in key worker } & \multicolumn{5}{|c|}{ Change in psychiatrist } \\
\hline & & $\begin{array}{l}\text { Mean } \\
\text { or } N(\%)\end{array}$ & $\begin{array}{l}\text { Odds } \\
\text { ratio }\end{array}$ & $\begin{array}{l}\text { 95\% confidence } \\
\text { interval }\end{array}$ & P & & $\begin{array}{l}\text { Mean } \\
\text { or } N(\%)\end{array}$ & $\begin{array}{l}\text { Odds } \\
\text { ratio }\end{array}$ & $\begin{array}{l}\text { 95\% confidence } \\
\text { interval }\end{array}$ & P \\
\hline \multirow[t]{3}{*}{ Care plan completed } & No change & $1223(82)$ & & & & No change & $1553(76)$ & & & \\
\hline & 1 change & $677(84)$ & 1.16 & 0.92 to 1.46 & 0.22 & 1 change & $683(78)$ & 1.10 & 0.91 to 1.34 & 0.31 \\
\hline & $>1$ change & $208(78)$ & 0.81 & 0.59 to 1.11 & 0.19 & $>1$ change & $196(66)$ & 0.61 & 0.47 to 0.80 & $<0.01$ \\
\hline \multirow[t]{3}{*}{ Involved in medication decisions } & No change & $1084(72)$ & & & & No change & 1465 (73) & & & \\
\hline & 1 change & $621(77)$ & 1.28 & 1.05 to 1.57 & 0.02 & 1 change & 634 (73) & 0.99 & 0.83 to 1.19 & 0.93 \\
\hline & $>1$ change & $173(66)$ & 0.73 & 0.55 to 0.96 & 0.02 & $>1$ change & $182(61)$ & 0.59 & 0.46 to 0.77 & $<0.01$ \\
\hline \multirow[t]{3}{*}{ Side-effects discussed } & No change & 1065 (71) & & & & No change & $1445(72)$ & & & \\
\hline & 1 change & $590(73)$ & 1.10 & 0.99 to 1.33 & 0.34 & 1 change & $623(71)$ & 0.97 & 0.81 to 1.15 & 0.70 \\
\hline & $>1$ change & $159(60)$ & 0.61 & 0.46 to 0.80 & $<0.01$ & $>1$ change & $164(55)$ & 0.48 & 0.37 to 0.62 & $<0.01$ \\
\hline \multirow[t]{3}{*}{ Physical health checks completed } & No change & $1150(75)$ & & & & No change & $1558(75)$ & & & \\
\hline & 1 change & $623(75)$ & 1.02 & 0.84 to 1.24 & 0.85 & 1 change & $685(76)$ & 1.07 & 0.89 to 1.28 & 0.50 \\
\hline & $>1$ change & $199(72)$ & 0.84 & 0.63 to 1.12 & 0.24 & $>1$ change & $204(66)$ & 0.66 & 0.51 to 0.85 & $<0.01$ \\
\hline \multirow[t]{3}{*}{ Received CBT received } & No change & 269 (19) & & & & No change & 330 (17) & & & \\
\hline & 1 change & 156 (21) & 1.10 & 0.88 to 1.37 & 0.42 & 1 change & 168 (21) & 1.23 & 0.99 to 1.51 & 0.06 \\
\hline & $>1$ change & $45(18)$ & 0.95 & 0.67 to 1.36 & 0.79 & $>1$ change & $59(21)$ & 1.27 & 0.93 to 1.74 & 0.14 \\
\hline \multirow[t]{3}{*}{ Received family therapy } & No change & $171(12)$ & & & & No change & $211(11)$ & & & \\
\hline & 1 change & $97(13)$ & 1.06 & 0.81 to 1.39 & 0.66 & 1 change & $113(14)$ & 1.28 & 1.00 to 1.63 & 0.05 \\
\hline & $>1$ change & 29 (12) & 0.96 & 0.63 to 1.46 & 0.85 & $>1$ change & $33(12)$ & 1.08 & 0.73 to 1.60 & 0.68 \\
\hline \multirow[t]{3}{*}{ Received employment support } & No change & $150(11)$ & & & & No change & $204(12)$ & & & \\
\hline & 1 change & 91 (13) & 1.15 & 0.87 to 1.52 & 0.31 & 1 change & $89(12)$ & 0.99 & 0.77 to 1.30 & 0.99 \\
\hline & $>1$ change & $24(11)$ & 0.92 & 0.58 to 1.45 & 0.72 & $>1$ change & $29(11)$ & 0.97 & 0.64 to 1.46 & 0.89 \\
\hline
\end{tabular}

patient knowing how to contact their key worker, strengthen the basis for believing that changes in clinical staff influence the quality of care that patients receive.

\section{Implications for clinical practice}

Our findings indicate that changes to staff providing care for people with schizophrenia could have negative impacts on various aspects of care, as well as patients' overall perception of and satisfaction with the care they receive. Although it is unrealistic to suggest changes to staff should or could be avoided altogether, efforts should be made to maintain relational continuity of service provision whenever possible. Factors associated with frequent changes of clinical staff include workforce stability and the extent of use of temporary staff. ${ }^{18}$ Over recent years, there has been considerable discussion about the costs and potential benefits of reorganising mental health services. These include a range of specialist community services and the development of separate teams for providing in-patient and out-patient care. ${ }^{19}$ New research is being undertaken to examine the impact that these types of changes have on patient outcomes, ${ }^{20}$ but available evidence to date suggests that patients often find the resulting changes in staff providing their care difficult. ${ }^{21}$ The results of this analysis suggest that changes in clinical staff may also have negative effects on the quality of care that patients receive. Our findings provide support for national guidelines in England that people using community mental health services should be supported by staff from a single team with whom they have a continuous relationship. ${ }^{1}$ Patients whose medical care is provided by rotating trainee are more likely to have experienced a change in their psychiatrist. It is essential that there is a proper handover when care is transferred from psychiatrist to another so that important information about current treatment and care is not lost.

\section{Acknowledgements}

The National Audit of Schizophrenia (NAS) is managed by the Royal College of Psychiatrists' College Centre for Quality Improvement (CCQI). It is commissioned by the Healthcare Quality Improvement Partnership as part of the National Clinical Audit and Patient Outcomes Programme. The views expressed in this publication are those of the authors and not necessarily those of the NHS, the National Institute for Health Research, or the Department of Health.

Rahil Sanatinia MD, Centre for Mental Health, Imperial College London, London, UK; Violet Cowan, BSC, Centre for Mental Health, Imperial College London, London, UK; Kirsten Barnicot, PhD, Centre for Mental Health, Imperial College London, London, UK; Krysia Zalewska, BSC, College Centre for Quality Improvement, Royal College of Psychiatrists, London, UK; David Shiers, MBChB MRCGP, College Centre for Quality Improvement, Royal College of Psychiatrists, London, UK; Stephen J. Cooper, $\mathrm{MD}$, College Centre for Quality Improvement, Royal College of Psychiatrists, London,

UK; Mike J. Crawford, MD, College Centre for Quality Improvement, Royal College of Psychiatrists, London, UK

Correspondence: Mike J. Crawford, College Centre for Quality Improvement, Royal College of Psychiatrists, 21 Prescot Street, London E1 8BB, UK. Email:

m.crawford@imperial.ac.uk

First received 3 May 2016, final revision 30 June 2016, accepted 8 Sep 2016

\section{References}

1 National Institute for Health and Care Excellence. Service User Experience in Adult Mental Health: Improving the Experience of Care for People Using Adult NHS Mental Health Services. NICE, 2011.

2 Horvitz-Lennon M, Kilbourne AM, Pincus HA. From silos to bridges: meeting the general health care needs of adults with severe mental illnesses. Health Aff 2006; 25: 659-69.

3 Tansella M, Thornicroft G, Lempp H. Lessons from community mental health to drive implementation in health care systems for people with long-term conditions. Int J Environ Res Public Health 2014; 11: 4714-28.

4 Crawford MJ, de Jonge E, Freeman GK, Weaver T. Providing continuity of care for people with severe mental illness: a narrative review. Soc Psychiatry Psychiatr Epidemiol 2004; 39: 265-72.

5 Jones IR, Ahmed N, Catty J, McLaren S, Rose D, Wykes T, et al. Illness careers and continuity of care in mental health services: a qualitative study of service users and carers. Soc Sci Med 2009; 69: 632-9.

6 Puntis S, Rugkasa J, Forrest A, Mitchell A, Burns T. Associations between continuity of care and patient outcomes in mental health care: a systematic review. Psychiatr Serv 2015; 66: 354-63.

7 Lehman AF, Postrado LT, Roth D, MCNary SW, Goldman HH. Continuity of care and client outcomes in the Robert Wood Johnson Foundation program on chronic mental illness. Milbank Q 1994; 72: 105-22.

8 Royal College of Psychiatrists. Report of the Second Round of the National Audit of Schizophrenia. Royal College of Psychiatrists, 2014. 
9 National Institute for Health and Care Excellence. Schizophrenia: Core Interventions in the Treatment and Management of Schizophrenia in Adults in Primary and Secondary Care. NICE, 2009.

10 Shipley K, Hilborn B, Hansell A, Tyrer J, Tyrer P. Patient satisfaction: a valid index of quality of care in a psychiatric service. Acta Psychiatr Scand 2000; 101: 330-3.

11 SPSS. SPSS version 22. IBM SPSS Statistics, 2014.

12 Holmes D. New initiative aims to tackle shortfalls in mental health crisis care Lancet Psychiatry 2014; 1: 15-6.

13 Johnson S, Needle J, Bindman JP, Thornicroft G. Crisis Resolution and Home Treatment in Mental Health. Cambridge University Press, 2008.

14 Gibson S, Hamilton S, James K. Evaluation of the Crisis Care Concordat Implementation. Final Report. McPin Foundation, 2016.

15 Thornicroft G. Physical health disparities and mental illness: the scandal of premature mortality. Br J Psychiatry 2011; 199: 441-2.

16 Crawford MJ, Jayakumar S, Lemmey SJ, Zalewska K, Patel MX, Cooper SJ, et al. Assessment and treatment of physical health problems among people with schizophrenia: national cross-sectional study. Br J Psychiatry 2014; 205: 473-7.
17 Hamann J, Langer B, Winkler V, Busch R, Cohen R, Leucht S, et al. Shared decision making for in-patients with schizophrenia. Acta Psychiatr Scand 2006; 114 265-73.

18 Belling R, Whittock M, McLaren S, Burns T, Catty J, Jones IR, et al. Achieving continuity of care: facilitators and barriers in community mental health teams. Implement Sci 2011; 6: 23

19 Omer S, Priebe S, Giacco D. Continuity across inpatient and outpatient mental health care or specialisation of teams? A systematic review. Eur Psychiatry 2015; 30: 258-70.

20 Giacco D, Bird VJ, McCrone P, Lorant V, Nicaise P, Pfennig A, et al. Specialised teams or personal continuity across inpatient and outpatient mental healthcare? Study protocol for a natural experiment. BMJ Open 2015.

21 Begum M, Brown K, Pelosi A, Crabb J, McTaggart J, Mitchell C, et al. Survey of patients' view on functional split of consultant psychiatrists. BMC Health Serv Res 2013; 13: 362 